${ }^{1}$ INSERM, Paris, France

${ }^{2}$ CEDEA, Universidad de Chile, Santiago, Chile

${ }^{3}$ Ministry of Health of Chile, School of Public Health Universidad de Chile, Santiago, Chile

${ }^{4}$ CIBISAP, Universidad de Santiago, Santiago, Chile ${ }^{5}$ Fundacion EPSON, Barcelona, España

${ }^{6}$ National Commission of Bioethics, Mexico DF, Mexico ${ }^{7}$ Institut für Wissenschaft und Ethik, Bonn, Germany ${ }^{8}$ FIOCRUZ, Rio de Janeiro, Brazil ${ }^{9}$ BIO\&SUR, Buenos Aires, Argentina

\section{Correspondence to} Dr Eugenia Lamas, INSERM 101 rue de Tolbiac, 75654 Paris Cedex 13, France; eugenia. lamas@inserm.fr

Received 11 March 2010 Revised 6 July 2010 Accepted 8 July 2010 Published Online First 26 August 2010

\title{
A comparative analysis of biomedical research ethics regulation systems in Europe and Latin America with regard to the protection of human subjects
}

\author{
Eugenia Lamas, ${ }^{1}$ Marcela Ferrer, ${ }^{2}$ Alberto Molina, ${ }_{1}^{1}$ Rodrigo Salinas, ${ }^{3}$ Adriana Hevia, ${ }^{4}$ \\ Alexandre Bota, ${ }^{5}$ Dafna Feinholz, ${ }^{6}$ Michael Fuchs, ${ }^{7}$ Roland Schramm, \\ Juan-Carlos Tealdi, ${ }^{9}$ Sergio Zorrilla ${ }^{4}$
}

\begin{abstract}
The European project European and Latin American Systems of Ethics Regulation of Biomedical Research Project (EULABOR) has carried out the first comparative analysis of ethics regulation systems for biomedical research in seven countries in Europe and Latin America, evaluating their roles in the protection of human subjects. We developed a conceptual and methodological framework defining 'ethics regulation system for biomedical research' as a set of actors, institutions, codes and laws involved in overseeing the ethics of biomedical research on humans. This framework allowed us to develop comprehensive national reports by conducting semi-structured interviews to key informants. These reports were summarised and analysed in a comparative analysis. The study showed that the regulatory framework for clinical research in these countries differ in scope. It showed that despite the different political contexts, actors involved and motivations for creating the regulation, in most of the studied countries it was the government who took the lead in setting up the system. The study also showed that Europe and Latin America are similar regarding national bodies and research ethics committees, but the Brazilian system has strong and noteworthy specificities.
\end{abstract}

\section{BACKGROUND}

During the 20th century, systematic procedures for drug experimentation on human subjects were developed through medical research. At the same time, the means for ensuring adequate protection for these subjects were developed. The early attempts to regulate experimentation were drafted in the Republic of Weimar at the beginning of the 20th century. ${ }^{1}$ The first recommendation, establishing that all countries are required to have an independent ethical review of medical research by research ethics committees (RECs), was the Declaration of Helsinki. This is one of the most widely accepted recommendations on this issue and was formulated by the World Medical Association in $1964 .^{2}$ Discussion and revisions of guidelines have continued since then. One of the latest to be amended is the International Ethical Guidelines for Biomedical Research Involving Human Subjects. The amendments were made by the Council for International Organizations of Medical Sciences, a joint initiative established by WHO and Unesco in $1949 .^{2}$ Given the globalisation of biomedical research, there is a need to identify and compare ethical regulation systems worldwide and to evaluate compliance with international standards for the protection of human subjects, with a special emphasis on informed consent and independent review by an REC (the two main requirements for ethical clinical research). ${ }^{3}$

Stronger ethical regulation systems can benefit populations, fostering healthcare research and medical innovations on crucial public health issues that are relevant for improving healthcare systems. This is particularly important for developing countries, as was explicitly stated in the Mexico Statement on Health Research, signed by more than 50 countries and convened by WHO. ${ }^{4}$

The European and Latin American Systems of Ethics Regulation of Biomedical Research Project (EULABOR), funded by the 6th Framework Programme of the European Commission and coordinated by the French Institute of Health and Medical Research (INSERM), is the first network linking Europe and Latin America in this domain. The academic institutions that compose EULABOR are shown in table 1 . The goal of EULABOR was to evaluate the systems of research ethics regulation and their compliance with internationally agreed standards of biomedical research on human subjects.

The study was conducted taking into account the socio-economical contexts in Argentina, Brazil, Chile, France, Germany, Mexico and Spain, and their relevance for the functioning of healthcare research regulation systems. In addition, EULABOR promoted dialogue and mutual understanding to make research and ethical reviews more transparent and to ensure compliance with ethics standards within different cultures.

We developed a conceptual framework to allow comparison of ethics regulation systems in different countries, aiming at its worldwide application. Other studies, limited in scope $e^{5}$ or restricted to a single country, ${ }^{6}$ have been conducted. Our study is the first comparative analysis of regulation systems in seven countries on two continents.

\section{METHODS}

Our conceptual framework defines the ethical regulation system of biomedical research as 'a set of actors, institutions, codes, and laws involved in overseeing the ethics of biomedical research on humans'. The system is dynamic and composed of three elements (figure 1). 
Table 1 Institutions that compose EULABOR (European and Latin American Systems of Ethics Regulation of Biomedical Research Comparative Analysis of their pertinence and application for the protection of human subjects)

\begin{tabular}{lll}
\hline Country & Institution & National coordinator \\
\hline Argentina & Bio \& Sur Foundation & Juan-Carlos Tealdi \\
Brazil & FIOCRUZ, Oswaldo Cruz Foundation & Roland Schramm \\
Chile & $\begin{array}{l}\text { University of Santiago de Chile, University } \\
\text { of Chile, Ministry of Health }\end{array}$ & Sergio Zorrilla \\
France & INSERM (French Institute of Health and & Eugenia Lamas \\
Germany & Medical Research) & Michael Fuchs \\
Mexico & IWE (Institut für Wissenschaft und Ethik) & Dafna Feinholz \\
Spain & National Commission of Bioethics & Alex Bota \\
\hline
\end{tabular}

1. Normative: institutions responsible for ethics regulations: REC, public regulatory bodies, normative and legal regulations.

2. Executive: entities that contribute to operating the system under the supervision of the normative constituents, which include associations of biomedical researchers, healthcare institutions, patients' associations, research-sponsoring organisations (eg, pharmaceutical companies), universities and research centres.

3. Contextual: national and international conditions that contribute to operating the system within a given economic, social, cultural and political environment.

In addition, related key questions were explored: the relationship between biomedical research and country health priorities; the policies regarding science and technology; and the pharmaceutical industry's role in defining regulatory frameworks and research agenda.

We developed a methodological framework to create national reports for comparative analysis from mainly primary information, obtained from interviews with key informants: representatives from RECs, public regulatory agencies, biomedical research associations, healthcare institutions, patients' associations, research sponsors, universities and research centres.
Using this framework, EULABOR's national teams described the system of ethics regulation of biomedical research in each of the seven countries involved in the project. A global and comparative analysis was then carried out. A database gathering the main results was developed. More details on the database and the methodology are available at EULABOR's website. ${ }^{\text {? }}$

\section{RESULTS}

Although Europe and Latin America appear to be similar with regard to normative elements, the level of involvement of competent authorities in ethics reviews and the enforcement of regulations differs among countries. The main results regarding regulatory frameworks, historical background, national bodies and RECs are as follows.

\section{Regulatory framework}

The national reports carried out by EULABOR's partners show that the regulatory framework for clinical research in these countries differ in scope. For example, the Mexican legislation covers only pharmaceutical research on non-registered drugs, epidemiological research and medical devices; Chilean legislation is less restrictive, while France, Germany and Spain have a more

Figure 1 Biomedical research ethics regulation systems.

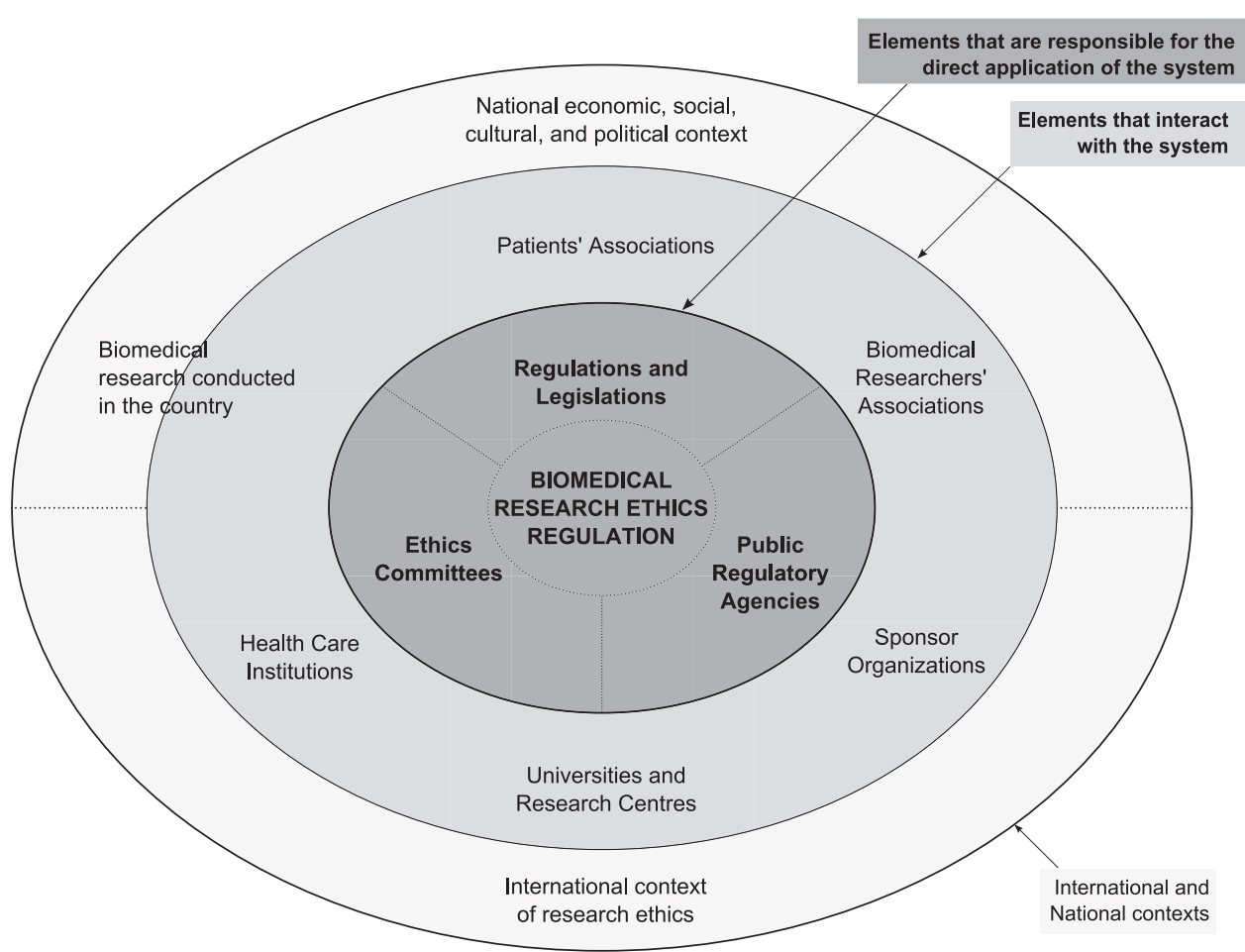


Table 2 Some aspects of the national bodies in the countries studied

\begin{tabular}{|c|c|c|c|c|c|c|c|}
\hline \multirow[b]{2}{*}{ National body } & \multicolumn{7}{|l|}{ Country } \\
\hline & Argentina & Brazil & Chile & Mexico & Germany & Spain & France \\
\hline Ministries & $\begin{array}{l}\text { National and } \\
\text { Regional Health } \\
\text { Ministry }\end{array}$ & CNS & $\begin{array}{l}\text { Ministry of } \\
\text { Health }\end{array}$ & $\begin{array}{l}\text { Ministry of } \\
\text { Health }\end{array}$ & $\begin{array}{l}\text { Federal Health } \\
\text { Ministry }\end{array}$ & $\begin{array}{l}\text { Ministry of } \\
\text { Health }\end{array}$ & DGS \\
\hline $\begin{array}{l}\text { Competent drug } \\
\text { authority }\end{array}$ & ANMAT & ANVISA & $\begin{array}{l}\text { Public } \\
\text { Health Institute }\end{array}$ & COFEPRIS & $\begin{array}{l}\text { Federal Institute } \\
\text { for Drugs and } \\
\text { Medical Devices }\end{array}$ & $\begin{array}{l}\text { Spanish Agency } \\
\text { of Drugs and } \\
\text { Healthcare Products }\end{array}$ & AFSSAPS \\
\hline $\begin{array}{l}\text { Nationwide entity in } \\
\text { charge of the ethical } \\
\text { regulation of research }\end{array}$ & No & CONEP & No & No & No & No & No \\
\hline $\begin{array}{l}\text { Bioethics national } \\
\text { commission or national committee }\end{array}$ & No & CONEP & No & $\begin{array}{l}\text { National } \\
\text { Bioethics Commission }\end{array}$ & $\begin{array}{l}\text { Nationaler } \\
\text { Ethikrat }\end{array}$ & No & CCNE \\
\hline
\end{tabular}

AFFSAPS, Agence française de sécurité sanitaire des produits de santé; ANMAT, Administración Nacional de Medicamentos, Alimentos y Tecnología Médica; ANVISA, Agência Nacional de Vigilância Sanitária; CCNE, Comité Consultatif National d'Ethique; CNS, Conselho Nacional de Saúde; COFEPRIS, Comisión Federal para la Protección contra Riesgos Sanitarios; CONEP, Comissão Nacional de Ética em Pesquisa; CONICYT, Commission Nacional de Investigación Cientifica y Tecnológica; DGS, Direction Générale de la Santé.

comprehensive legislation including several types of research. Nevertheless, all national regulations have been inspired, even implicitly, by international agreements such as the Declaration of Helsinki, Council for International Organizations of Medical Sciences Guidelines, International Conference on Harmonisation of Technical Requirements for Registration of Response (ICH) Guidelines for Good Clinical Practice, and the Convention of Oviedo. As members of the European Union (EU), France, Germany and Spain have passed the European Directive on Good Clinical Practice (2001/20/CE) into law. ${ }^{7}$

\section{Historical background}

From a historical perspective, the national reports showed that the political context, actors involved and motivations for creating the regulation systems varied among countries. ${ }^{7}$ In Germany, the medical profession established, under public law, a nationwide system of ethics committees for the evaluation of research proposals and recommendations to researchers. In Brazil, the starting point was a national debate on human rights and public health that took place after the recovery of democracy. In Mexico and Argentina, national government and academic institutions provided the motivation to update international standards. In France, there were two simultaneous motivating factors: a strong political will and pressure from the national pharmaceutical industry. The pressure from the international pharmaceutical industry also had an important role in Chile and Argentina. Finally, in Spain the motivation for creating the regulatory framework was the harmonisation with EU membership requirements. In spite of different actors involved, in all countries except Germany the government took the lead in setting up a regulatory system. The national reports of this study showed, however, that the level of governmental involvement in the overseeing of respect for research ethics is related to the level of development of the country itself.

\section{National bodies}

Table 2 shows the national bodies in charge of research ethics in the countries studied. The Ministry of Health and drug regulation authorities are involved in all the countries in overseeing the ethical aspects of medical research. In addition, Germany, France, Mexico and Brazil have a specific national committee that render opinions on ethical and societal issues raised by the advances made in biomedicine and health. In addition to this role, the Brazilian National Commission for Research Ethics (CONEP) is responsible for establishing regulations for ethical issues in research. ${ }^{8}$ CONEP also registers all protocols evaluated by any Brazilian REC and plays an important role in the protection of human subjects participating in medical research. Indeed, CONEP is in charge of evaluating protocols addressing a number of special categories (ie, research on indigenous people, human reproduction, biosafety, medical devices, human genetics and research conducted abroad). None of the other countries studied oversees research protocols in the way that Brazil does.

\section{RECS}

As shown in table 3, all the countries studied have RECs that evaluate protocols on research conducted on human subjects. Its composition, tasks and funding do not differ significantly. The membership of a community representative is mandatory only in Chile, France and Brazil. In all the countries studied except Brazil and France, RECs receive a payment for the ethical review. However, REC members, except for private RECs in Chile and Argentina, do not receive any payment for the assessment. Table 3 shows also that all European countries studied have an accreditation system, while among Latin American countries only Brazil has an official system.

Other issues from Brazil are noteworthy. This is the only country whose RECs receive clinical trial results when research is completed, and require a commitment from the researcher to make the results public. The importance of this issue has been broadly debated by the medical community. Only Brazilian RECs have adequate resources compared with other countries, which generally acknowledge a lack of resources. The network connecting RECs, through the CONEP, is also particularly active.

Finally, the semi-structured interviews with key informants showed that in all countries studied (see table 3 ) the general public is not adequately informed about the existence, functioning and scope of RECs. Along with this lack of information there is a great demand for training programmes for RECs members, these needs being met mostly by academic institutions. ${ }^{7}$

\section{CONCLUSION}

The performance of a regulatory system, within a given economic, social, cultural and political environment, depends largely on the characteristics of its normative and executive constituents. Such an environment may favour an ethical regulation system if, for instance, it has a consolidated democracy or provides universal healthcare. Conversely, obstacles may hinder the system if, for example, large sectors of the population live in poverty, or if there is low involvement of the government 
Table 3 Some aspects of the research ethics committees (RECs) in the countries studied

\begin{tabular}{|c|c|c|c|c|c|c|c|}
\hline \multirow[b]{2}{*}{ REC } & \multicolumn{7}{|l|}{ Country } \\
\hline & Argentina & Brazil & Chile & Mexico & Germany & Spain & France \\
\hline Composition: interdisciplinary (+gender) & Yes & Yes & Yes & No & Yes & Yes & Yes \\
\hline $\begin{array}{l}\text { Obligatory inclusion of the community } \\
\text { representative }\end{array}$ & No & Yes & Yes & No & No & No & Yes \\
\hline Minimum number of members for quorum & 5 & 7 & 8 & 3 & Not determined by law & 9 & 12 \\
\hline \multicolumn{8}{|l|}{ REC's functions } \\
\hline Ethical & Yes & Yes & Yes & Yes & Yes & Yes & Yes \\
\hline Legal & Yes & Yes & Yes & No & Yes & Yes & Yes \\
\hline Scientific & Yes & Yes & Yes & No & No & Yes & Yes \\
\hline Payment for the assessment & In some cases & No & Yes & Yes & Yes & Yes & No \\
\hline Payment to members & Only for private RECs & No & Only for private RECs & No & No & No & No \\
\hline $\begin{array}{l}\text { RECs receive the results after research is } \\
\text { finished }\end{array}$ & No & Yes & No & No & No & No & No \\
\hline RECs resources are sufficient & No & Yes & No & No & Variable & Variable & No \\
\hline National network of RECs & Yes & Yes & No & No & Yes & Yes & Yes \\
\hline RECs are accredited & No & Yes & No & No & Yes & Yes & Yes \\
\hline
\end{tabular}

or low empowerment of civil society. Moreover, the international aspects of research ethics that include international agreements and regulations, and the activities of transnational pharmaceutical companies, have a bearing on how countries implement their systems.

The uniqueness of the EULABOR project is based on gathering empirical data on ethics regulatory systems of biomedical research in seven countries, each having strong national identities and situated on two different continents. This study offers a conceptual framework for designing and evaluating policies concerning the protection of human subjects participating in biomedical research, and allows comparisons among countries. The EULABOR database has been created to make this information available, and it will be updated periodically. ${ }^{7}$

The results of our study show that developing and intermediate countries can make important advances and create strong ethics regulation systems. Indeed, this is the case for Brazil, whose system of regulation of research ethics has some unique characteristics, making it even more dependable than those currently in place in the European countries studied in this project. The sharing of this knowledge resulted in the improvement of local regulatory systems as a direct outcome of this project, as is the case in Chile, where a regulatory system is being set up in part as a consequence of the participation in this project by the Chilean Ministry of Health. We hope the EULABOR database will help other countries to design, initiate or improve ethics regulation systems for biomedical research that effectively protect the rights of human subjects.

Acknowledgements We thank all the individuals who took part in the work of the EULABOR project (listed by country and then alphabetically by name): Argentina:
Ignacio Maglio, Maria Luisa Pfeiffer, Juan Carlos Tealdi (team leader); Brasil: Heloisa Helena Barboza, Anibal Guimaraes, Marisa Palacios, Sergio Rego, Fermin Roland Schramm (team leader), Miriam Ventura da Silva, Laís Záu Serpa de Araújo; Chile: Marcela Ferrer, Adriana Hevia, Rodrigo Salinas, Sergio Zorrilla Fuenzalida (team leader); France: Pierre Boitte, Armelle de Bouvet, Eugenia Lamas (team leader), Alberto Molina; Germany: Michael Fuchs; Mexico: Elizabeth Cuéllar Barroso, Dafna Feinholz (team leader), César Lara, José Ramón Ramírez Gorostiza, Guillermo Soberón; Spain: Alex Bota Arqué (team leader), Josep Maria Esquirol, Silvia Miguel, Ramón Rius. We warmly acknowledge Anne Fagot-Largeault and Vincent Guillin for their review, and Alain Johnson for English translation of this paper.

Funding This work was supported by the European Commission under FP6 Science and Society programme (SAS 6-517861).

Competing interests None.

Provenance and peer review Not commissioned; externally peer reviewed.

\section{REFERENCES}

1. Howard-Jones N. Human experimentation in historical and ethical perspectives. Soc Sci Med 1982;16:1429-48.

2. Delfosse ML, Bert C. Bioéthique, droits de l'homme et biodroit. 2nd edn. Brussels: Larcier 2009:360, 375.

3. Emmanuel $\mathbf{E}$, Wendler D, Grady C. What makes clinical research ethical. JAMA 2000;283:2701-11.

4. World Health Organization. The Mexico statement on health research. Knowledge for better health: strengthening health systems, 2004 (updated 11 Dec 2008). http:// www.who.int/rpc/summit/en/index7.html (accessed 10 Mar 2010).

5. Kirigia J, Wambembe C. Status of national health research systems in ten countries of the WHO African Region. BMC Health Serv Res 2006;6:135. http://www. biomedcentral.com/1472-6963/6/135 (accessed 10 Mar 2010).

6. Carvalho F. Regulation of clinical research and bioethics in Portugal. Bioethics 2007;21:290-302

7. EULABOR. European and Latin American Ethical Regulation Systems of Biomedical Research: Comparative Analysis of its Pertinence and Application for Human Subject Protection, 2009. http://www.eulabor.org (accessed 10 Mar 2010).

8. Conselho Nacional de Saúde. Comissão Nacional de Ética em Pesquisa (CONEP). http://conselho.saude.gov.br/comissao/eticapesq.htm (accessed 2 Feb 2010). 


\section{JME}

\section{A comparative analysis of biomedical research ethics regulation systems in Europe and Latin America with regard to the protection of human subjects}

Eugenia Lamas, Marcela Ferrer, Alberto Molina, et al.

J Med Ethics 2010 36: 750-753 originally published online August 26, 2010

doi: 10.1136/jme.2009.035097

Updated information and services can be found at:

http://jme.bmj.com/content/36/12/750.full.html

These include:

References This article cites 4 articles

http://jme.bmj.com/content/36/12/750.full.html\#ref-list-1

Email alerting Receive free email alerts when new articles cite this article. Sign up in service the box at the top right corner of the online article.

Topic Articles on similar topics can be found in the following collections

Collections

Research and publication ethics (352 articles)

Notes

To request permissions go to:

http://group.bmj.com/group/rights-licensing/permissions

To order reprints go to:

http://journals.bmj.com/cgi/reprintform

To subscribe to BMJ go to:

http://group.bmj.com/subscribe/ 